\title{
Tentativa de tratamento específico, por meio da ticlopidina, de pacientes com doença de Chagas em fase crônica
}

\author{
An attempt of specific treatment by means of ticlopidine of \\ patients with chronic phase of Chagas' disease
}

\author{
Anis Rassi, Vicente Amato Neto, Gustavo Gabriel Rassi, \\ Francisco Ferriolli Filho e Valdir Sabbaga Amato
}

Resumo Em investigação experimental, a ticlopidina mostrou ser ativa no sentido de diminuir a parasitemia e a mortalidade quando avaliada a infecção de camundongos pelo Trypanosoma cruzi. Por isso, este fármaco foi administrado a 12 pacientes com doença de Chagas, em fase crônica. Houve utilização de 150, 200 ou 250mg, durante 90 dias, conforme se tratasse de crianças, adolescentes ou adultos, respectivamente. Ficou documentado cabal insucesso sob os pontos de vista parasitológico e sorológico.

Palavras-chaves: Fase crônica da doença de Chagas. Ticloplidina. Tentativa de tratamento específico.

Abstract In a previous study, ticlopidine decreased the parasitemy and mortality of mice infected by Trypanosoma cruzi. Therefore, this drug was administered to 12 patients with Chagas' disease, in the chronic phase. For 90 days, 150, 200 or $250 \mathrm{mg}$ were utilized according to whether the recipients were children, adolescents or adults, respectively. A fully unsuccessful outcome was documented, both sorologically as well as parasitologically.

Key-words: Chronic phase of Chagas' disease. Ticlopidine. Specific treatment.

Para o tratamento específico da infecção humana devida ao Trypanosoma cruzi contamos atualmente com o benznidazol e com o nifurtimox, cujos resultados ainda deixam a desejar, seja pelo grau de eficácia, seja pela ocorrência de efeitos colaterais, às vezes motivadores de interrupção do emprego dos mesmos. Há, então, necessidade de progressos, sobretudo agora, quando se concede proeminência à participação do parasita no contexto das múltiplas hipóteses patogenéticas concernentes à doença de Chagas.

Em virtude do exposto, julgamos adequado efetuar observação de caráter terapêutico, usando ticlopidina ${ }^{3}$, em virtude de interesse por parte de instituições francesas (Sanofi Recherche e Institut National de la Santé et de la Recherche, Médicale - INSERM), tendo Kieffer G, Tobelem $G$ e Degos $L$ participado como assessores científicos, que referiram resultados satisfatórios decorrentes de investigação experimental em camundongos $\mathrm{C}_{3} \mathrm{H} / \mathrm{HeJ}$, infectados por meio de inoculação da cepa CL do T. cruzi. Houve diminuição da mortalidade e da parasitemia, enquanto que todos os animais do grupo utilizado como controle morreram. O fármaco foi administrado no decurso de 21 dias. Para explicar a atividade antiparasitária admitiu-se que tem lugar efeito inibitório do composto na ligação da fibronectina ao protozoário.

Faculdade de Medicina da Universidade Federal de Goiás e Hospital "São Salvador", Goiânia, GO, Brasil. Endereço para correspondência: Dr. Anis Rassi. Av. A 333, Setor Oeste, 74110-020 Goiânia, GO, Brasil.

Fax: 5562 281-8097.

Recebido para publicação em 30/8/99. 
O protocolo seguido teve coerência com diretrizes demarcadas por nós e pelos membros dos órgãos solicitantes do estudo que realizamos.

Doze pacientes com doença de Chagas crônica constituíram nossa casuística (seis do sexo masculino, quatro crianças, dois adolescentes e seis adultos). Antes do tratamento, em quatro ocasiões, mensalmente, providenciamos a execução de xenodiagnóstico e de provas sorológicas (imunoflorescência indireta ${ }^{1}$ e fixação do complemento ${ }^{2}$ ). Sempre cada xenodiagnóstico ficou composto por quatro caixas com dez ninfas cada, de terceiro estádio do Triatoma infestans. Positividades deste exame e dos testes sorológicos representaram critérios para inclusão dos doentes na pesquisa.

O esquema adotado para usar a ticlopidina correspondeu à administração oral de 150, 200 ou $250 \mathrm{mg}$ a cada 12 horas, durante 90 dias, conforme se tratasse de crianças, adolescentes ou adultos, respectivamente.

Como controle da atividade terapêutica recorremos ao xenodiagnóstico e às provas sorológicas mencionados, efetuados a cada mês, em seguida ao término do emprego do fármaco em questão. Incluímos também eletrocardiograma e hemograma, com contagem de plaquetas, em repetidas determinações.

Não aconteceram manifestações colaterais dignas de registro.

O xenodiagnóstico indicou positividade em todos os pacientes, nos seguintes momentos e números de casos: primeiro mês - 5; segundo mês - 3; terceiro mês - 1; quinto mês - 1; sétimo mês - 1; décimo-sexto mês - 1. Não verificamos modificações quanto aos resultados positivos e teores de anticorpos detectados, ao considerarmos os exames sorológicos.

Portanto, de acordo com a metodologia escolhida, concluímos que a ticlopidina foi totalmente ineficaz, contrariando a perspectiva decorrente da pesquisa prévia praticada em camundongos.

Convém salientar que a maneira segundo a qual agimos é apropriada para levar a cabo análise como a que efetivamos. Permite dedução irrefutável e deixa patente que o número de xenodiagnósticos não pode ser pequeno e a etapa de seguimento não pode ser curta, valendo rememorar que em um caso o xenodiagnóstico documentou falha do tratamento somente no $16^{\circ}$ exame após o fim do uso do composto sob avaliação.

\section{REFERÊNCIAS BIBLIOGRÁFICAS}

1. Camargo ME. Introdução às técnicas de imunofluorescência. Revista Brasileira de Patologia Clínica 9:57-71, 87-107, 143-171, 1974.

2. Freitas JLP, Almeida JO. Nova técnica de fixação do complemento para moléstia de Chagas (Reação quantitativa com antígeno gelificado de culturas de Trypanosoma cruzi). O Hospital 35:789-800, 1949.
3. Panak E, Maffrand JP, Picard-Fraire C, Valée E, Blanchard J. Roncucci R. Ticlopidine: a promise for the prevention and treatment of thrombosis and its complications. Haemostasis 13 (supl 1):1-54, 1983. 